\title{
Practices, Challenges and Prospects of Competency Based Instruction in Some Selected Primary Schools in Case of Sidama Zone.
}

\author{
Dancho Desalegn Sirika \\ School of Education, Hawassa College of Teacher education, \\ PO box 115, Hawassa, Ethiopia
}

\begin{abstract}
In this study qualitative research design particularly phenomenological approach was employed. Because the purpose of this study was to investigate practices, challenges and prospects of competency based instruction in primary schools. One primary school selected from the Sidama zone through criterion based Sampling technique and 10 teachers were selected through available sampling technique from sample selected schools. Semi-structured interview was held with participants. Results revealed that, competency based teaching approaches are not well implemented in primary schools in research study area. The main reason for this is there was knowledge gape with primary school teachers to implement competency based teaching instructions. Thus, it is concluded that more efforts need to be devoted in the development of teachers understanding of competency based teaching approaches. Keywords: Competency, Instruction, Assessment, constructivism
\end{abstract}

DOI: $10.7176 / \mathrm{JEP} / 12-1-06$

Publication date: January $31^{\text {st }} 2021$

\section{Introduction}

One of the general objective of education and training policy of Ethiopia is to develop the physical and mental potential and the problem solving capacity of individuals by expanding education with the moto of basic universal primary education for all. In line with this the Ethiopia education development roadmap (unpublished material), plan to introduce competence based comprehensive approach focusing on practical teaching learning activities. Practical, life skills and aesthetics contents enhance the development of problem solving and creative minds need to be incorporated into the curriculum (MoE 2018).

According to Kabita \& Ji (2017), competency based instruction is emphasizing what learners are expected to do rather than mainly focusing on what they are expected to know. In principle, such instruction is learner-centered and adaptive to the changing needs of students, teachers and society. It implies that learners can acquire and apply the knowledge, skills, values, and attitudes to solve situations they encounter in their everyday life.

As defined by Le et al (2014), in a competency based model, the level of expectation for student learning is high for all students with each student responsible for meeting established learning goals that is competencies. In addition to this, the competency based education defined by Le et al (2014), achieving competency means that a student has mastered both academic knowledge and skills, as well as other cognitive, intrapersonal and interpersonal skills. Therefore, the approach will make learning meaningful and provide opportunities to apply the competencies to real life situations, while also empowering them with skills for lifelong learning.

To ensure that all students succeed in meeting learning targets, educators provide more personalized learning opportunities and supports and allow students to learn at varying times and places, assess their learning when they are ready and progress at their own pace. Despite affording students greater flexibility and support, students in competency based education settings can earn credit only when they have demonstrated mastery of established learning targets.

\section{Statement of the problem}

Today, our country faced serious social, political and economic challenges, including ethnic-related strife. Furthermore, the country is struggling with social ills, especially among the youths, like drugs and substance abuse and rebellious behaviour. For the adult population, there are many challenges caused by corruption and negative ethnicity. In millions number of adult were unemployed. Due to this, locking educational system is important to address the problems.

On an other hand, as discussed in Ethiopian education development roadmap (unpublished material), the problem solving skills which promote critical and livelihood skills are not given due attention in the primary education curriculum. Due to this, graduates of primary education lack competence which requires integration of knowledge, skills and the necessary values (MoE 2018).

In 2010, an EGRA conducted literacy student on Grades 2 and 3 and showed that children in primary first cycle were not developing the basic skills required to learn effectively in later years. Especially in Sidama zone, $69 \%$ of students in Grade 2 were unable to read a single word of a grade-level relevant story (MoE 2010). In line with this, the annually report of Sidama zone educational department showed that majority of the primary school 
students tend to have little motivation, interest and commitment in their education. There are also, competency problem between the students.

The national needs assessment study revealed that the majority of Ethiopia perceived education as a powerful tool to reverse the current dire social and economic challenges the country faces, like high rates of unemployment and underemployment (MOE 2018). Therefore, the researcher believes that to answering the following research questions will be help to address these problems.

\subsection{Research Questions}

1. What is the practise of competence based instruction among primary schools in Sidama zone?

2. To what extent the current teaching learning approach is relevant in providing opportunity to apply the competencies to real life situations and empowering learners with skills for lifelong learning?

3. What are the challenges that hinder the effective implementation of competence based instruction?

4. How the identified challenges be harnessed to implement competence based instruction effectively?

\subsection{General Objective}

Competency based instruction

\subsubsection{Specific Objectives}

To achieve the general objective of the study, the following specific objectives have been sated.

1. To analyze practice of competency based instruction among primary schools in Sidama zone.

2. To discuss the relevance of current teaching learning approach to provide opportunities to apply the competencies to real life situations and empowering learners with skills for lifelong learning.

3. To find challenges of competency based instructional implementation in primary education.

4. To suggest learning experiences that promotes achievement of the competency descriptors.

\subsection{Theoretical framework}

The study was guided by constructivists' theory. The main concept of constructivism is that teaching with constructivism methods involves the learners being active participants in the classroom (Solso, 2009). He further asserts that constructivism is grounded on the fact that for children to expand their learning they need to explores their environment and learns from hands on experiences.

\subsection{Ethical Considerations}

The researcher provided clue for the respondents about the research and that the study was for academic purpose only. It was made clear that participation is voluntary and the respondents were free to decline or withdraw anytime during the research period. The respondents were not coerced into participating in the study. The participants were informed consent to make the choice to participate or not. They were guaranteed that their privacy was protected by strict standard of anonymity. High standard of professionalism was observed as the researcher avoided fabricating or altering result by scientists to suit her study.

\subsection{Definition of Terms}

Competency is an integrated set of knowledge, skills and attitudes that enables one to effectively perform the activities of a given expected standard (MoE K-12 Curriculum framework 2009/10 E.C).

Instructional strategies are techniques teachers use to help students become independent, strategic learners.

\section{Research Methodology}

\subsection{Research Design}

In this study qualitative research design of phenomenological approach was employed. Because the major goal of this study is to investigate the practice, challenges and prospective of competency based instruction and gather detail information concerning current education approach to provides opportunities to apply the competencies to real life situations. These method aims, to answer questions about the what, how or why of a phenomenon rather than how many or how much, which are answered by quantitative methods (Patton \& Cochran 2002). Therefore, qualitative research can help us to interpret and better understand the complex reality of a given situation and the implications of quantitative data.

\subsection{Source of data}

To answer the basic research questions of this study, the required data was collected using primary and secondary sources. The primary sources of data were teachers who have been teaching in governmental primary schools. Because they are directly concerned with the issue under the study.

The secondary sources of data were unpublished documents like annual and weekly teachers lesson plan. 


\subsection{Sampling techniques}

The population of this study was teachers who have been teaching in governmental primary schools in Sidama zone. The representatives of population were selected through mixed sampling technique. Criterion based Sampling technique was employed to select primary schools. Criterion sampling involves selecting cases that meet some predetermined criterion of importance (Patton, 2001, p. 238). Therefore, criterion for selection is model schools in 2011 E.C of Sidama zone and taking the $1^{\text {st }}$ ranked school. Because, qualitative research is usually focus on a small number of sample. Available sampling technique was employed to select teachers from sub selected sample school.

\subsection{Sample size}

Many qualitative researchers state that sample size and sampling designs are not issues in qualitative research. Same researchers discussed that sample size may estimate based on the approach of the study or the data collection method used. For each approach there are some related rules of thumb. As discussed by Dukes (1984), Smith et.al. (2009) and Creswell (1998) recommended interviews with up to 10 people in phenomenological research.

Hennink, Kaiser and Marconi (2017) consider sample size in relation to saturation or redundancy (where no additional issue are identified). But appropriate sample size depends on a numbers of factors specific to the study concerned and level of study for student work. In this study, 10 primary school teachers were participated.

\subsection{Instrument of Data collection}

In this study two types of data gathering instruments were used, namely documents analysis and face-to-face interview. The interview was Semi-structured. This is helpful that every respondent is asked the same questions. Therefore, it allowed for comparison of the answers from all the respondents. Existing literature (Kyale \& Brinkman, 2009; Marshall \& Rossman, 2010) coincides in that the phenomenological interview should be open or semi-structured. The documents were teachers' lesson plans.

\subsection{Methods of Data Analysis}

After collecting the necessary data carefully, the data was analysed through Narration (reformulate stories presented by people in different contexts and based on their different experiences). textual analysis (description of what is expressed by the participants), structural analysis (interpretation of how it is expressed by the participants) and essence description. According to Moustakas (1994), data analysis in phenomenology is characterized by identifying common meanings and essences, "horizontalization" of data, textual and structural analysis.

Table 1: - The basic demographic information about the key participants (to protect kps' anonymity, identifying information has been removed).

\begin{tabular}{|c|c|c|c|c|c|c|}
\hline $\begin{array}{l}\text { Participants } \\
\text { (kp) }\end{array}$ & Sex & Age & $\begin{array}{l}\text { Marital } \\
\text { states }\end{array}$ & Experience & level of education & $\begin{array}{l}\text { Grade level of } \\
\text { current teach }\end{array}$ \\
\hline $\mathrm{Kp} 1$ & Male & 33 & Married & 11 years & $1^{\text {st }}$ degree student & Grade $7 \& 8$ \\
\hline $\mathrm{Kp} 2$ & Male & 41 & Married & 16 years & $1^{\text {st }}$ degree & Grade $5 \& 6$ \\
\hline Kp 3 & Female & 28 & Single & 6 years & College diploma & Grade 4 \\
\hline $\mathrm{Kp} 4$ & Male & 39 & Married & 14 years & $1^{\text {st }}$ degree student & Grade $8 \mathrm{~A}-\mathrm{C}$ \\
\hline $\mathrm{Kp} 5$ & Male & 30 & Married & 10 years & College diploma & Grade 3 \\
\hline $\mathrm{Kp} 6$ & Male & 40 & Married & 18 years & $1^{\text {st }}$ degree student & Grade 7A\&B \\
\hline $\mathrm{Kp} 7$ & Male & 34 & Married & 12 years & $1^{\text {st }}$ degree & Grade $6,7 \& 8$ \\
\hline $\mathrm{Kp} 8$ & Female & 30 & Married & 13 years & College diploma & Grade 2 \\
\hline Kp 9 & Male & 31 & Married & 9 years & $1^{\text {st }}$ degree & Grade 5A\&B \\
\hline $\mathrm{Kp} 10$ & Female & 28 & Married & 7 years & $1^{\text {st }}$ degree student & Grade $6 \& 7$ \\
\hline
\end{tabular}

Most of participants have more than 6 years' experience in primary schools. Some of them had the responsibility in different positions. This makes them an important resource for this study. One of the participants mentioned that:

I am experienced as I have taught for 12 years in different primary schools, and you see me now working at a primary school. The experience that I have helps me a lot when I come across challenges in my work (Kp 7).

From the above information it is clear that the participants find their experiences very helpful, because they noted that in most cases they refer to the manner in which they had once overcome the challenges that came their way, especially if the situations are more or less similar. This makes them a reliable source for this study because they have much experience of the teaching in primary schools.

The participants were qualified teachers with primary education qualifications level. Out of ten teachers those who have participated in this study three teachers completed their first degree, four are working towards completing their first degrees while the remaining ones have just completed their higher diplomas in mathematics. Therefore, 
the students have advantage by learning the qualified teachers. When asked about their qualifications, one of them indicated as follows:

I think that my qualifications are fine because I don't struggle to teach the learners. I have the first degrees in mathematics from the University of Hawaasa. In addition to this I have participated in different short time training in different time. This makes me work with ease as I have the necessary background knowledge (Kp 2).

It is clear from the above responses that teachers were very proud of their educational qualifications. More importantly their qualifications placed them in a good position to teach effectively. They have also the ability to translate the subject content into classroom teaching that is suitable for the learners.

During the discussion the participants asked specifically about how do you use competence based instruction in lesson. Among the many ways that the discussed most of the participants highlighted that simply they were teaching to cover their lesson as well as the contents of text book.

I do not understand the meaning of competence-based instruction and how to implement in class room. When I was teaching in class room I used usual approaches. After presenting my lesson I was evaluate my students either to achieve objects or not through giving class work or home work (Kp 3, 5, 8).

Some of them also consider that, main practice of implementation of competence based instruction by simply attaching with the active learning approach.

In my class room there are slow learners, middle learners and fast learners. Based on their achievement I form group of five members and included one student from the high achiever of the class, one student from the low achiever of the class and three students from the middle achiever of the class. A student who understands a concept can share his or her ideas and strategies with other students. I motivate them to learn best from one another (Kp 6).

In their response when asked about from what base they were constructing questions, most of them use students text books. Some of them use other supplemental books and references.

After when I covering the content I was evaluate my students through giving quiz, tests, mid exam and final exam. Sometimes, I was used oral questions during the lesson. The questions contain different items like, true and false, multiple choice, matching and short answers. I was used text books and other references to construct the questions (Kp 2, 4, 9, 10).

From the above response the methods of deliver and responses of questions were written and oral. No one deliver and responses questions through practical. Similar they were asked how to measure difficult level and quality of questions. Their response was cross cheeking with stakeholders like department head and other teachers.

When I was prepared questions for the exam, our department head cheek the relevance of questions and he put his sign before duplicating the exam. But I was give quizzes and class activities without cheeking the department head (Kp 1, 3, 6, 10).

Participants were asked to rate the current teaching and learning approach based on students' effectiveness. Their response was the primary school students tend to have little motivation, interest and commitment in their education. In addition to this they are week for critical thinking, problem solving skill, creativity, analysing the idea and reasoning skills.

Usually in Mathematics I give them classwork to do every day but they cannot perform better in class. I give them the homework tasks every day. Similarly, they came to school without doing their homework. I see to it that they require a lot of practice ( $\mathrm{Kp} \mathrm{3).}$

Participants also mentioned the challenges that hinder the implementation of competence based instructions. Among the problems mentioned by participants lack of awareness of teachers how to implement competency based approach and how to align the activities and question with competency.

I do not understand how to construct the competence based activities and questions (Kp 1).

The teachers were asked how to enhance competence based instruction implementations in class room. Their responses were giving practice based activities, evaluating learners based on objective, follow the student centred teaching learning approach and making conducive teaching learning environments.

To creating responsible, confidential, creative and potential citizens for the future was very difficult. It should not be the work of the teachers alone to shape their future. Everyone must play his/her role. Even the approaches which we follow was student centred, their result was very low. Therefore, it is important to check our methodology (Kp 9).

\section{Conclusion}

The purpose of this study was to assess the extent to which competency based instruction is implemented in primary schools in Sidama zone. The study particularly focused on were the competency based teaching practices as applied in competency based approaches. Findings of the study clearly show that primary school teachers not able to provide the correct attributes of competency based teaching approaches. Instead they ended up listing only 
the components of the student centered teaching approaches.

The findings from this study are indicating that teachers were not well oriented to the practices of competency based teaching approaches and from where the competency select. Majority of them were not able to construct the competence based questions and inability to apply competency based approaches is lesson plan preparation. Constructing competency based questions do not necessarily need to be graded, but may be used assess student progress, keep track of how students are mastering content over time, and adjust/modify instructional approaches (Lorenz Lassnigg 2015).

Theoretically there is evidence that in Ethiopia the educational approach for primary schools gives emphasis to implement competency based instruction, active learning and continuous classroom assessment but practical don't implemented. The Ministry of Education guidelines state that teachers need to carry out regular checks on the progress of all students in each subject through continuous and formal assessment (MoE, 2010).

The major factors that hinder the implementation of competence based instruction was the knowledge gape of primary schools' teachers.

The conclusion of these findings hold that competency based teaching approaches are not well implemented in primary schools in Sidama zone. The major factor for this is there was a gape with primary schools' teachers to acquire sufficient and applicable knowledge about competency based approaches. It was notable that teachers reported being unaware of competence based instruction, alignment of the questions with competency, how to evaluate the level of difficulty and fairness of the questions. Thus, it is concluded that more efforts need to be devoted in the development of teachers understanding of competency based teaching approaches.

As discussed by (Lorenz Lassnigg 2015), the assessments were made on the basis of a proper statement of competency, proper statement of teachers' activities, proper statement of the students' activities and the students' assessment plans. In line with this, the MoE (2018) out lined that the competency selects from subject syllabus/teacher's guide and the relevant and appropriate question construct using the template given below.

Table 2: - Question constructing sample template

\begin{tabular}{|c|c|c|c|c|c|}
\hline Subject & & Grade: & $\mathbf{U}$ & r Week & Sem. \\
\hline Skill/Content /Titel: & & & & & \\
\hline Sub-Skill/Sub-content: & & & & & \\
\hline Competency: & & & & & \\
\hline $\begin{array}{l}\text { Method of Delivery: } \\
\text { Oral } \square \text {, Written } \square \text {, Practical } \square\end{array}$ & & $\begin{array}{l}\text { Type of } \\
\text { Question }\end{array}$ & $\begin{array}{l}\text { Multiple } \\
\text { Choice }\end{array}$ & $\begin{array}{c}\text { Constructed } \\
\text { Response }\end{array}$ & $\begin{array}{c}\text { Perfomance } \\
\text { Task }\end{array}$ \\
\hline $\begin{array}{l}\text { Method of Response: } \\
\text { Oral } \square \text {, Written } \square \text {,Practical } \square\end{array}$ & $\subseteq$ & Knowledge & Recall & Understanding & Application \\
\hline Question: & है & Attitude & Receiving & Responding & Valuing \\
\hline & & Skill & Imitation & Manipulation & Precision \\
\hline & & $\begin{array}{l}\text { Difficulty } \\
\text { Level }\end{array}$ & Easy & Moderate & Difficult \\
\hline Answer: & & Question & Valid & Fair & Efficient \\
\hline Rubric: & & $\begin{array}{l}\text { Quality } \\
\text { Criteria }\end{array}$ & Reliable & Objective & Acceptable \\
\hline
\end{tabular}

Source: MoE 2018, Continuous Classroom Assessment for Learning (CCAfL) Workbook.

\section{References}

Bernard HR (1995) "Research Methods in Anthropology", Second Edition. London: Sage Publications, 1995. David Njeng'ere Kabita, Lili Ji (2017) “The Why, What and How of Competency-Based Curriculum Reforms" The Kenyan Experience.

Kvale, S., \& Brinkman, S. (2009) "InterViews: Learning the Craft of Qualitative Research Interviewing." (2nd. ed). Thousands Oaks, CA:Sage.

Le, C , Wolfe, R , \& Steinberg, A (2014) “The past and the promise: Today's competency education movement. Students at the Center": Competency Education Research Series Boston, MA: Jobs for the Future.

Lorenz Lassnigg (2015) "Competence-based education and educational effectiveness" http://irihs.ihs.ac.at/3852. Marshall, C. \& Rossman, G. B. (2010) “Designing Qualitative Research” (5th ed.). Thousand Oaks, CA: Sage Publications.

Michael Quinn Patton and Michael Cochran (2002) "A Guide To Using Qualitative Research Methodology" MoE (2018). "Ethiopian Education Development Roadmap (2018-30)" Education Strategy Center (ESC) 
..(2010). "Education Sector Development Programme V (ESDP V)".

Moustakas, C. (1994). "Phenomenological Research Methods" Thousands Oaks, CA: Sage

\section{Biography}

Dancho Desaleng is a lecturer in Hawassa College of teacher education with a decade of successful experience in teaching and leadership. Dancho was born in Ethiopia Sidama national regional state special in Bensa Daye since 06/ 04/1987. Dancho has Masters Degrees in school leadership and Computational Mathematics from Hawassa University in Ethiopia since July 04, 2016 and July 02, 2015 respectively. Dancho is a strong believer in the power of positive thinking in the workplace. Please email daniyabd9@gmail.com address to contact Dancho.

\section{APPENDIX A}

Interview Questions for Participants

1, Questions that seek to probe the background of the interviewee

1. Tell me about your experience: what grade(s) are you teaching and your highest qualification.

2, Practice and Trend

2. How do you use competence based activities in lesson?

3. What is your base to constructing competence based questions?

4. How do you measure difficult level and quality criteria of questions?

5. How do you rate the current teaching and learning approach based on students' effectiveness?

6. What are the challenges to implement competence based instructions in class room?

7. How to enhance competence based instruction implementations in class room? 